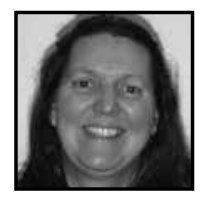

\title{
The Canadian Forest School Movement
}

\author{
Zabe MacEachren, Queen's University
}

\section{ABSTRACT}

This article documents the rationale and benefits of Forest Schools, while also describing why the organization Forest School Canada was formed. It is based on interviews with two people: Heather Andrachuk, a new teacher in a forest school, and Marlene Powers, a founder of two forest schools and the executive director of Forest School Canada. Narrations from these two women are used to describe the ethos and the pedagogy that results from working within Forest Schools and the origins of Forest School Canada (2013). It also briefly outlines the way Forest Schools serve as an approach to environmental education for early childhood through the development of a sense of attachment to nature.

\section{Introduction}

\begin{abstract}
magine a first day at school where your parents drop you off not at a building, but at the edge of a forest. You see no playground, just trees and meadows. A smiling teacher greets you and invites you to place your lunch in her large pack basket. You sit on a log in a small circle and meet your classmates for the year. You will soon be spending the rest of the day exploring your "classroom," which others call "nature." You will come to view plants, stones, and animals as fascinating teachers that capture your curiosity with new seasonal changes to notice every day. This could be a first day of school for a Forest Kindergarten student.
\end{abstract}

This article is based on two interviews I conducted with Marlene Powers and Heather Andrachuk. Marlene has taught in and founded both a Forest Preschool and a Kindergarten. She later hired Heather Andrachuk to teach at the Forest Kindergarten 
because she wanted to dedicate her time to launching Forest School Canada (FSC), the national organization that supports others' efforts to create nature-based programs for early childhood. Today, Marlene is the executive director of FSC. Heather Andrachuk graduated from the Queen's University Faculty of Education Outdoor and Experiential Education program and went directly into her first teaching position as a FS Kindergarten teacher. Heather's ideas offer a first-time teacher's account of the preparation required to teach outdoors all day. The interviews with Marlene and Heather begin to document the development of Forest Schools (FSs) in Canada. They describe the ethos and rationale of FSs, the reason why FSC was created, the benefits and pedagogy resulting from teaching outdoors, and the way FSs fill a gap by providing both a playbased and an environmental education for very young children.

\section{Forest Schools Ethos}

FSs can occur in many natural settings and can be identified by many terms (forest and farm program, field and forest program, nature kindergarten, etc.). The fundamental idea of a FS is to create opportunities for children to spend more time playing/ learning in natural settings. The term FS is generally used to represent a broad ethos based upon getting children outside to learn directly from nature in a play-based pedagogy (Cree \& McCree, 2012). Marlene states that FSs are based upon promoting "regular, repeated access to a natural space, which could be a farm, a forest, a municipal park, a conservation site, a beach, any natural space that children have a long period of time to build a relationship with and be in." Also unique to a FS is the way the place becomes a teacher and the way the human teacher encourages children to learn from nature. The use of play in a natural setting is what establishes FS as a unique pedagogy different from conventional environmental education curricula. Marlene states:

The defining feature is the emergent and play-based curriculum; I think it is fundamental to a FS and is what differentiates a FS from any other environmental program. Environmental education has a rich history and has so much to offer to schools and educators in Canada, but FS education is not about a defined way to do something.

FSs have increased in popularity as early childcare options because parents and teachers recognize the health benefits of promoting outdoor activities and a play-based learning pedagogy. 
The FS movement first originated in the Scandinavian countries, where popular culture prides itself on outdoor living. About 15 years ago, the FS idea was established in the UK through the development of practitioner courses (O'Brien \& Murray, 2006). In 2007, Marlene opened Carp Ridge Preschool, outside of Ottawa, the first FS in Canada. Today the movement is catching on quickly around the world.

\section{Ethos and Rationale for Forest Schools in Canada}

Marlene's desire to establish Carp Ridge Forest preschool was sparked when she noticed a gap in what was available in Early Childhood Education (ECE) programs. In our interview, she describes how her degree in Social Work had led to work experiences where she used environmental education as a means of therapy and a way of developing community capacity. As a passionate environmentalist and outdoor enthusiast, she noticed how the two fields fit nicely together. After moving to Ottawa in 2006 and acquiring a child development position with Childrens' Aid, she became involved with day cares and cooperative nurseries. Her professional work immersed her in researching alternative education programs and curricula for Early Childhood Education (ECE), and she quickly became aware of how little environmental education was being offered to very young children.

There is growing public awareness that each generation seems to be spending less time outdoors and more time indoors engaged with our prolific technological devices. Marlene's awareness of these changes was highlighted in her recollection of growing up in Newfoundland. She described her family's practice of living off the land and explained how "sustainability was embedded in their culture," even though it was "a term that they would never have used." She recalled that she and her twin sister, from the age of three on, had been sent out to play in the forest and on rocky beaches all day and were expected to come home and indoors only in order to fulfill their "primal need to eat or sleep." The idea of an early childhood centre was "not even a concept that [she] had heard of until [her] early years in university." Marlene's motivation to find a suitable program for young children also came from recognizing that her own current connection to the natural world was not as strong as it had been in her childhood. She resonated strongly with a popular book published at this time, "Last Child Left in the Woods," by Richard Louv (2005), which coined the term "nature-deficit-disorder." She was seeking a program for the young children she was working with that would offer the freedom she remembered from her childhood in Newfoundland. 
Marlene's first encounter with the idea of an FS came through reading Carl Honoré's 2008 book, "Under Pressure: Rescuing Childhood From the Culture of Hyper-Parenting," in which he mentioned an FS in China: She clearly recalls that moment when all her interests came together. As she was then pregnant for the first time, she aspired to make available such a program for her own children. This initial reading about FSs led to much more intensive research on the subject. She contacted FSs around the world and asked them how they began and for other valuable information regarding their administration and teaching responsibilities.

\section{The Organization: Forest School Canada}

After realizing the work involved in establishing two successful FS programs at Carp Ridge (the preschool and kindergarten) (2013), Marlene turned her focus to providing support for others to establish similar outdoor-based programs, especially for young children. Her success at Carp Ridge and previous research and networking had established her as a Canadian leader on this subject. She started to be invited to make presentations at Early Childhood Educational events and Environmental Education conferences. As she tried to support others' efforts to take children routinely outdoors, she realized that a more formal institution was required. Marlene wrote several proposals and was successful at obtaining various forms of support that allowed her, in 2012, to found and become Executive Director of Forest School Canada (FSC). Marlene's intention was to begin to create a network for support, education, and accreditation for concepts associated with the FS movement in Canada. As part of FSC's launch, she arranged for Clair Warden, a leading researcher and promoter of Forest Schools around the world, to come and lead workshops and webinars. Clair Warden founded Mindstretchers in Scotland and has authored numerous curriculum-based books that offer teachers support and provide a rationale for ways to promote fundamental outdoor learning experiences for students (Warden, 2013).

In the summer and fall of 2013, FSC offered pilot practitioner courses across Canada to aid educators in fulfilling their interest in establishing and working in FS settings. The pilot courses were based upon a practitioner program developed in the UK that uses a three-level course model (UK Forest School Association and Training at Bishop's Woods), but was also grounded in the realities of the Canadian experience. The plan is to eventually establish a means to educate and certify FS educators in Canada. A certifying organization is required to establish guidelines and standards of practice for taking 
very young children outside in order to address the public's concerns and to ensure that the benefits of FSs are not forgotten.

In a practitioner program, teachers would learn how to use a play-based and naturefocused pedagogy in their programs, as well as how to ensure it is done in a safe learning environment. Foremost is the idea of preventing any unfortunate accident from happening at a future FS. Many Canadian outdoor educators realize that the only benefit of the 1978 Timiskiming disaster (when 13 school children died in a canoeing accident) was the establishment of ORCKA: the Ontario Recreational Canoeing and Kayaking Association (Raffan, 2003). Like ORCKA and other similar certifying agencies, FSC plans to establish safe standards of practice and training opportunities for educators to learn ways to effectively take very young children outdoors.

Heather Andrachuk, who was present at the FSC launch, stressed the idea Claire Warden shared about the importance of teachers learning to distinguish risks from hazards. Heather shared accounts of young children learning to take healthy risks for their growth and development. Ensuring that such ideas become established in professional FS teachers' education is a prime example of the way an organization like FSC can serve educators. Many teachers have limited personal experience with being outdoors and even less working effectively with children in natural settings so everyone remains safe. Most teachers need to learn effective ways to allow children to learn to take appropriate risks for their abilities in natural settings beyond a schoolyard. In the UK and Scandinavian countries, many FS children are taught to handle hatchets, knives, and fires in a safe manner under the guidance of their teachers. Most current Canadian teachers need guidance themselves in order to use such tools and to establish safe practices with children. As well as establishing guidelines and protocol for establishing FSs, FSC is also part of a team that is designing a model FS facility at Ottawa's Equestrian Park. Policy research and initiatives will continue to evolve through FSC and the Ottawa FS model site; the aim is to establish evidence and give priority to the value in FS programs.

Currently, the various FSs that are running are mostly associated with private schools. Marlene expressed a strong interest in bringing the ethos of Forest Schools into the public school system through the work of FSC. One example does exist. In British Columbia, a Nature Kindergarten has been started within the Sooke District School Board, which makes it the first public-based program in Canada. Marlene is exploring how FSC can make links with universities so that teacher candidates and continuing teacher education courses can encourage the ethos behind Forest Schools and promote safe, educational learning opportunities for children in the public school systems. 
Environmental educators support the FS model because it provides an authentic and enriched means for children to learn based upon the extended periods of time they would spend outdoors in nature. An example exists in Denmark, where the concept of Forest Schools extends into the higher grades: weekly or biweekly for one day, a whole school moves to a local natural area to conduct all of its daily subjects (Mygind, 2011). Danish teachers have come to expect to teach all their subjects outside one day a week. As more and more Canadian parents and teachers recognize the rewards of teaching and learning outdoors, such a practice may also begin to occur in Canada. As Marlene articulated: "When outdoor learning is routine for young children, they will begin to demand being outside as they grow up."

\section{Benefits of Forest Schools}

Very young children receive many benefits from spending their formative years outside. Being outdoors provides diverse learning opportunities, which indoor confined spaces do not offer. Health benefits arise from an environment that challenges physical ability, including fine and gross motor skills. Empowering respect for and love of nature results as time spent learning outdoors is increased. A sense of self is reaffirmed as confidence grows through the continued sharing of new adventures with friends and teachers.

Marlene elaborated on a few learning exceptionalities that do well in FSs and mentioned the research that is just beginning in this area (Pavey, 2006). For instance, she described children with autism who do better in the outdoors where sound does not bounce off walls and individuals with hyper-activity who benefit from fully expending their energy so that learning patterns are not interrupted. Marlene explained:

For children with autism and ADHD, there has been documentation of benefits. Because an outdoor space doesn't have walls, the noise is not as loud, it does not over stimulate. Children in an FS can often walk away from situations; [they can] take a breath or take time away if they are getting overwhelmed. With four walls, they can't do that as easily because [learners walking out of a classroom] are harder to supervise. People think it would be harder to supervise [learners] outdoors, but I think it is easier [outdoors] to manage those behaviours."

Other children with exceptionalities who tend to do better in FS than in conventional schools include those who are hyperactive or who have ADHD. There is still no 
conclusive research to support any claim, but some initial studies are demonstrating that being immersed in natural colours and views rather than in bright colours, as are often found on children's toys, may have a calming effect on children (Norton, 2006; Hoicowitx, McNerney, Jidspm, \& McCoy, 2003). Other research has noted the beneficial role natural sounds can have on calming individuals (Lakovides, Illiadou, Bizeli, Kaprinix, \& Fountoulakis, 2004).

Heather offered specific narrations of individual students benefitting from an FS curriculum. One incident she outlined involved a student who loved the FS program but was very clumsy moving through the woods, which early on resulted in bruises and sore spots that required her to rest at home. After a discussion with the child's parents, Heather specifically started to help the child slow down and think through more complex movements over logs and branches. She said the results of this guidance were very positive. Rob McDougall, Outdoor Education Coordinator for Gould Lake Outdoor Centre, mentioned that he is surprised at how many more children are twisting their ankles and struggling to move on uneven ground; he could not recall previous years at the Outdoor Centre when as many little injuries occurred as in the past two years (McDougall, 2013). Rob suspects that some children are spending most of their lives moving only on level surfaces such as flat floors, stairs or escalators, and manicured, leveled fields; the children's formative years of development lack the diverse terrain that would require them to make subtle ankle shifts as they balance and move on hillsides or uneven ground, as frequently occurs in natural settings. Carla Hannaford's 2005 book Smart Moves provides many details concerning the role various movements play in child development-at both the physical and neurological levels. Many of her examples outline the complexity of outdoor movement compared to movements done with standardized apparatus. Outdoor movement on varied terrain provides enriched learning opportunities for coordination, neural development, balance, and overall fitness. Heather provided specific accounts of the way her students' physical growth and self-confidence were improved throughout the year as she provided guidance and reminders to them as they repeatedly attempted various climbing routes they encountered throughout the FS day.

Whereas FSs benefit children with specific learning needs and individuals who need more varied terrain for full physical development, all children benefit from FSs through the opportunity they provide to establish a deep fascination with the natural world. Heather shared a detailed account of one incident that clearly transformed an energetic group of boys for the year. Visitors to the Carp Ridge Centre told Heather that they had just seen a great horned owl. Heather immediately got the students to don the 
snowsuits they had just taken off for lunch in the wall tent, so that they could try to spot the owl on this very cold February day. Eventually, a few of them spotted the owl; they all quietly moved closer until they had a good view of the bird. Heather explained:

I did not have to say anything or prepare the children at all, but they knew this was a really important, awe-inspiring experience. This was a group of very active boys who normally were not quiet in any sense of the word. There was not a peep out of any of them; they just watched [the bird]. The bird was spinning its head, looking at us and looking away. When the children wanted to speak, they spoke in whispers, asking such questions as: "What is it doing? What is it looking for? What kind of things does it eat? What sounds does it make?" The children were absolutely enraptured: no complaints about being hungry or being cold; jaws open and eyes wide.

This owl-spotting experience would be an event that the children referred to throughout the rest of the year. Heather emphasized her amazement at having children mention that they wanted to make the sound of a mouse under the snow so that "maybe the owl will fly again and maybe it will come at us and we can see more of it." Another child commented that the owl was the same size as his baby brother. Encounters with other beings, as occur in natural settings, provide an ideal learning atmosphere that allows children's curiosity to become both focused and expansive as they make connections to their own lives.

As children are allowed to follow their whims and explore their interests in nature, so too do they explore and develop a confidence and sense of who they are. Marlene shared one of her proudest moments, which involved her daughter Hazel, who she described as "super quirky and funny and a real firecracker of a character." When Hazel started FS, remembered Marlene, she was afraid to walk on ice and be near water. Marlene continued:

I remember seeing her in the FS with her frilly ballerina tutu on in the rain, with full rain gear, with mud gear filled with mud, and her doll under her arm. [I was proud] to see how she could still be who she is and still have her fears and different neuroses and quirks, and to see how she can still love being outdoors. [Now] every day she goes down to the river at home, and she loves it. Seeing my children live that way is what I am most proud of. I am sure that the Forest School is a big part of that, but also it has so influenced and affirmed how I parent.

It is hoped that FSC will be able to provide a means to do research and better document the benefits FSs seem to offer, so that other educators and parents will feel supported in 
including more outdoor learning opportunities in their practices. The goal is to expose students to nature more often in order to improve their health and learning and to enrich their overall development.

\section{Developing Pedagogy for Forest Schools}

The social context created in an FS setting, which does not have the confinements of walls, offers a unique opportunity for interactions between nature and child, teacher and child, and classmates and child. All of these interactions offer a rich means to foster language and communication skills. For the FS teacher, the setting requires different behaviour management techniques. Heather realized quite quickly in her teaching experience that she needed to involve students in the planning of the day. Involving students in planning their learning is not new in education, but unfortunately it is still not a standard practice that all teacher candidates are assured of experiencing on their practicum. Some teaching styles or school curricula encourage open-ended structure and a large degree of student-determined inputs (Summerhill School, 2004; Central Advisory Council for Education, 1972). Such open teaching and learning styles need to be encountered routinely in order to become part of an established teacher's practice. Heather had to sort out many things on her own because she worked alone in a unique setting that required flexibility. Similar to A.S. Neills's Summerhill Free School, she found a solution in a self-designed, consensus-based process that involved her young children's input (Summerhill School, 2004). She explained:

The biggest challenge that stood out for me was learning about behaviour management in a different setting than an educator might have in a conventional setting with four walls and typical classroom resources. It was a lot of trial and error for me and for the students to learn about how we would cooperate-the kind of dance we would do and what would work best. I learned that I did not have to be doing a lot of the classroom management and curtailing a lot of what the children were doing. Rather, I could create an environment for them that would allow them to be themselves and be comfortable in the space they would create for themselves.

A lot of my practice revolves around democracy with the children [with] each of us having an equal voice. I am not the boss of them, and they are not the boss of me, and each of us is the boss of ourselves. We all have our voice and advocacy. That really helped me in learning about them and what would work for them in this different setting: In the morning, we have what I call our morning meeting. And that is, 
for the most part, the only time during the day that I really like to require the children to be part of what we are doing. The rest of the day, they get to choose what they participate in or don't want to do, and I facilitate that. But in the morning, I find it really important for us to set up expectations for the day, to "touch base on how we are feeling," what we are bringing that day emotionally, socially, from home what is happening, anything exciting or interesting or upsetting in their lives. And then we plan the day from there. Everyone gets a say in what we are interested in doing for the day and what we might like to undertake. And then we "map out the day" based upon that. For the most part, we can come to consensus on that. I prefer to come to consensus rather than compromising because, to me, when you compromise, no one ever really gets what they want; but, for me, when we come to consensus, it means everyone gets what they want.

Heather's explanation of the way the group created a schedule for a day is based on young people's ability to move between familiar terrain and the construct of a map. As a professional outdoor educator who frequently teaches navigational skills, I was very intrigued to listen to Heather's descriptions of her students' sense of direction and wayfinding ability. Future research may be able to address the role that exposure in early years to wandering freely outside provides, such as a sense of direction in adults. I have, a few times, experienced university students afraid to enter small woodlots in case they could not find their way out. I also have noticed teachers' growing dependence on navigational devices, such as GPS, and struggles to follow a map or teach mapping skills to others. Heather's mapping and planning a day seems to invite future research that explores how routine childhood wandering influences a sense of direction:

When we literally map out the day, the children are very amazing to me. I mean four-, five-, and six-year-olds are amazing. I mean amazing at understanding landscape and direction once they become comfortable with a site. We will often create a map and physically draw it out in the snow, sand, or dirt or use objects such as twigs and rocks and leaves, to make a map. Then [we] use it to talk about what we are going to do and how we are going to get from place to place, where we are going to go, and in what order we are going to do things. Then we get to talk about it; for example: "If we go there, we might not have time to do this [thing] that you wanted." Then I ask: "Are you OK with that? If we can't do your thing [today], is it OK if we start the next day with it?" And most often it is no problem at all.

Heather has demonstrated a confidence in her own ability to learn and adapt a pedagogy for teaching in the outdoors. Heather's narrations also emphasized the rich language and cognitive development that these children develop by learning how to 
express themselves using constructs of time, place, and the need to be considerate of one's classmates. Heather uses her morning circle to plan a day and give rhythm to her yearly cycle. She then accompanies the children as a group as they wander and loosely follow the plan they set forth in their morning circle. As she travels all day with the children, she circulates through small group conversations aiming to add ideas that build upon their initial awareness and interest. She takes her clues from their observations and role models new observations, terms, and additional questions to encourage their curiosity and further intrigue in the subject. Her awareness of curriculum guidelines is brought to the foreground of an interaction after a student makes an initial related inquiry. For instance, if a student notices an insect has a certain number of legs, Heather may then encourage all insect legs to be counted by the children and compared to what they have seen on previous days. Both the social dynamics of a forest school and the opportunity to become aware of changing natural phenomena provide rich settings for developing language skills.

\section{Forest Schools as an Approach to Environmental Education and Play-Based Education}

Both Marlene's and Heather's commentaries emphasize the rich environmental skills and relationship to place that FS students develop. Heather is uniquely capable of commenting upon this because her graduate research focused on citizen science programming. Citizen science is based on educating local citizens in ways to accurately document various natural phenomena and their yearly changes (e.g., monarch butterfly migrations, yearly bird and frog monitoring counts). Such documentation has proven very valuable to scientists and environmental advocacy groups. Heather referred to being continually impressed by the natural phenomena these young children notice, such as the distinction between insects found in the forest versus fields. Heather's FS students constantly find new insects and ask questions she is unsure how to answer, but she loves the research she is continually called upon to do so that the next time a phenomenon is noticed she can introduce students to new terms and dialogue to further encourage their problem-solving and questioning skills.

Nature provides children with an infinite number of reasons to ask questions and dialogue with teachers and peers about what they are observing. The opportunities nature provides to spark student interests are unmatched by any computer program, once students learn the language and terminology associated with following their curiosity. Some of what motivates people to start an FS is the recognition that children of all 
ages, including early childhood, need to be offered an enriched opportunity to develop eco-literacy. Marlene emphasized the way an FS provides the ability "to understand the life cycle, handle natural and sustainable materials, and offers the everyday opportunities to raise ideas about personal impact and compassion." She concluded that,

her number one driving force for establishing an FS was to try and infuse that sense of passion, inquiry, inspiration, and attachment to the natural world, with the hopes that it will have long-lasting impacts on how we live and the kind of leaders we are creating for the future.

Both Marlene and Heather are dedicated to the idea that to be a professional educator in an FS means that you must have a strong understanding of the way play-centred learning in nature can unfold and know how to use an emerging curriculum based upon what is noticed in the learning site each day. Many Early Childhood Education programs already use or are turning towards a child-centred, play-based learning approach (for example, Ontario's all-day kindergarten curriculum). However, FSs' emphasis on allowing the natural features of a place to teach the children may be new to many educators. Marlene describes how a teacher can work with an evolving sense of play instead of fully directing or controlling every situation:

I think it is a lot harder to be an educator who knows how to stimulate, [be] active and engaged and creative and imaginative and [offer] child-directed learning - and then get out of the way.... [Often teaching] is too directed: "I am the expert; I know everything; I am the teacher." That kind of teacher takes control over a situation. The process of teaching in an emerging context and knowing when to be involved and when to get out of children's way takes a very skilled, educated, intuitive, and imaginative educator. Our hope is that FSC shapes the education field, not just to give children an opportunity to be in an education setting like this, but also to give educators an opportunity to teach in this way, in a more inspiring, intuitive, and imaginative way.

Marlene also raised the ideas that FSs benefit individual educators working in them and in the general field of environmental education:

The FS movement empowers everyday educators, not just outdoor educators or people who have taken a university OEE program .... All educators are encouraged to take ownership and to be responsible for teaching environmental education. I think that the future of environmental education needs to be rooted in everyday 
experience, in bringing nature into the promotion of environmental education so that it connects us to the environment we are teaching about.

Marlene has been impressed with the "very vibrant and engaged and passionate educators" who are seeking her out and asking her how they can do practicums at a FS.

Most environmental curricula, similar to many subject-based lesson plans, have well-defined curricula that flow from one predetermined activity to another, so that each step sequentially builds skills and concepts. However, a play-based curriculum allows children to follow their own curiosity about the natural phenomena that they are immersed in, while also having teachers and peers to interact with and converse with on the topic, so that their ideas and skills can be expanded in various directions depending upon the situation and its emergent opportunities. Marlene describes how a teacher's ability to use an emergent curriculum is one of the clear distinctions between conventional environmental education programs and FS curricula.

Both Marlene and Heather are passionate about using FSs to build children's primary attachments to the natural world in, as Marlene stated, "the same way we are building attachments to humans." Building attachment to nature requires a continued opportunity to be in nature and to recognize how human life is dependent upon natural systems and a healthy environment. FSs use the natural world at a critical time in children's development to build their healthy, caring sense of a place.

\section{Conclusion}

In today's world of prolific technological devices, of manicured playing fields and school grounds, and of enclosed buildings, it is inspiring to know that the FS movement is catching on and finding its way in Canada. The confidence, practices, and environmental awareness that an FS education offers young children is clearly needed today. Through FSC's practitioner courses and research that help to create safe standards of care and articulate the value of such programs, it is hoped that the FS movement will continue to grow and produce the leaders that will be needed to address future environmental issues. As Marlene states: "One of the powerful things about the FS movement for the environmental education field is that it acknowledges, legitimizes, and brings environmental education into the early years, a really critical time for attachment." As FSs create attachment to the natural world, they also offer a rich environment in which children (and educators) develop into healthy, confident, caring citizens. 


\section{Acknowledgment}

I would like to thank Marlene Powers and Heather Andrachuk for consenting to participate in the interviews.

\section{References}

Carp Ridge Preschool \& Forest Kindergarten. (2013). Retrieved from http://www.carprid gelearningcentre.ca/index.html

Central Advisory Council for Education (England). (1972). Children and their primary schools ("The Plowden Report"). In Nyquist, E., and Hawes, G. Open Education (pp. 23-45)

Cree, J., \& McCree, M. (2012). A brief history of the roots of forest schools in the UK. In Horizons (60), Winter.

Forest School Canada. (2013). Retrieved from http://www.forestschoolcanada.ca/

Hannaford, C. (2005). Smart moves. Utah: Great River Books,

Hoicowitz, A., McNerney, A., Jidspm. L., \& McCoy R. (2003, October 15). Final 1: How color affects mood. Retrieved from http:// jrscience.wcp.muohio.edu/nsfall99/labpacketArticles/Final1.HowColorAffectsMoo. html

Honoré, C. (2008). Under pressure: Rescuing childhood from the culture of hyper-parenting. New York: Harper Collins Publishers.

Krusekopf, F. (2013). Nature Kindergarten Sooke School District. Retrieved from http://nature kindergarten.sd62.bc.ca/proposal/

Lakovides, S., Illiadou, V., Bizeli, V., Kaprinix, S., \& Fountoulakis, K. (2004, March 24).

Psychophysiology and Psychoacoustics of Music: Perception of Complex Sound in Normal Subjects and Psychiatric Patients. Annals of General Hospital Psychiatry. Retrieved from http://www.ncbi.nlm.nih.gov/pmc/articles/ PMC400748/
Louv, R. (2005). Last child left in the woods. NC: Algonquin Books

McDougall, R. (2013). (Personal Correspondence, September 24, 2013)

Mygind, E. (2011). (Personal Correspondence) For a brief abstract in English, also see http:// www.udeskole.dk/site/udeskole/678/

Norton, L. (2006, August, 2006). What Color is your mood. Department of Psychology Missouri Western State University. Retrieved from http://clearinghouse.missouriwestern. edu/manuscripts/817.php

O'Brien, L., \& Murray, R. (2006). A marvellous opportunity for children to learn, A participatory evaluation of forest school in england and wales. Surrey, UK: Forest Retrieved from http://www.forestry.gov.uk/pdf/fr0112forest schoolsreport.pdf/\$FILE/fr0112forestscho olsreport.pdf

Pavey, B. (2006). The forest school and inclusion: a project evaluation. Retrieved from (http://www.leeds.ac.uk/educol/docu ments/161165.htm)

Raffan, J. (2003). Deep waters is adventure worth the risk-the lake timiskaming canoeing tragedy. Harper Collins, Canada: Phyllis Bruce Books

Summerhill School. (2004). Retrieved from http://www.summerhillschool.co.uk/

Warden, C. (2013). Mindstretcher. Retrieved from http://www.mindstretchers.co.uk/category. cfm?category_ID=211 


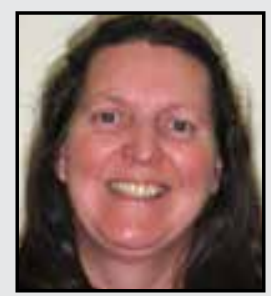

Zabe MacEachren is the Outdoor and Experiential Education coordinator for Queen's University at the Faculty of Education. She is an avid outdoor travel and environmental educator with a specialty in examining how we learn about the environment by making things from the materials found there. One of her motivations to research Forest School Canada was because she passes a preschool every day on her way to and from work and feels saddened by the artificial grass and plastic play structures the children are limited to exploring.

LINK TO:

http://www.forestschoolcanada.ca 